\title{
- BOOK REVIEW - \\ How to KILl a DRAGON \\ aspects of Indo-European linguistics
}

\author{
Marc G. L'Heureux
}

By Calvert Watkins. New York, New York: Oxford University Press, 1995 [2001PB]. PP. XIII+613. ISBN 97801951441320. HB\$135.00/PB \$40.00.

Calvert Watkins' How to kill a dragon argues that the comparative method used by linguists for the last several hundred years may be used in the realm of poetics, as well: just as the comparative method allows linguists to reconstruct structures of Proto-Indo-European (a hypothetical ancestor of most of the languages of Europe and many of those from India and the Middle East), it also allows the reconstruction of poetic features of the protolanguage.

After briefly discussing the history of comparative Indo-European linguistics and its methods and produce, Watkins turns to laying the framework for a comparative study of poetical features. His central features are formulas, "set phrases which are the vehicles of themes", which in turn make up "the culture of the given society" (Watkins 9). Watkins states his goal as being "to emphasize the longevity and specificity of verbal tradition and the persistence of specific verbal traditions, whether in the structures of the lexicon, or syntax, or of style" (Watkins Io).

The book is divided into two major subsections, each comprising approximately half of the length of the main text: the first, "Aspects of Indo-European poetics" deals mostly with the history and theory of that field, and provides the equipped reader with a background necessary to understand case studies provided by Watkins and follow his novel argument in part II; in part II Watkins synthesizes his research relating 
"dragon slaying" formulas in the various Indo-European languages and ultimately proves, by way of reconstruction, that the formula was present in the "poetic repertory" of Proto-Indo-European, and its development may be followed through most of the branches of the language family.

The first six chapters of part I act as an introduction to the history and methodology of Indo-European poetics. Watkins begins in earnest by exploring the histories of what he considers to be the three main branches of Indo-European poetics: formulaics, which deals with semantically cognate phrases comprised of lexically cognate elements in cognate languages; metrics, which deals with line scansion; and stylistics, which he describes using Jakobson's words as "what makes a verbal message a work of art" (Jakobson 63).

Watkins provides the reader with an inventory of poetic devices and grammatical rules evidenced by the Indo-European poetic traditions. Following a discussion of the importance of certain phonological devices, especially phonetic indexing and ring structures (Watkins 29ff.), Watkins notes that such devices are little "relevant" (Watkins 37) to meaning, which is better understood by studying poetic diction and poetic syntax; however, "an overview of poetic diction... would amount to a discussion of the dictionary of each language" (Watkins 38). At this point Watkins refines the definition of "formula" to be entire phrases used repeatedly with little variation; such formulas are the focus of the rest of the book.

The remaining chapters of part I deal with the art of the poet and his role in preserving formulas through the passage of time. Watkins outlines the reciprocal nature of the relationship between patron and poet, itself reconstructed based on evidence from Indo-European texts (Watkins 68ff.). Poets were also (again based on the evidence of reconstruction) curators of great power, and this power was derived from the words which they spoke (Watkins 85ff.); as such, these words which they spoke ceremonially or in some official manner were spoken with "particularity and precision", and thus became preserved as poetic formulas (Watkins 9I).

Part II consists of ten chapters featuring a wide variety of case studies and samples that illustrate Watkins' points about poetic grammar and the fixation of poetic formulas. Particularly engaging is the discussion of the "antecedents" (Watkins 136 ) of tragic performance in old IndoEuropean religious rituals. The evidence is drawn from Anatolian inscriptions, almost all of which describe in great detail religious rituals. Reneging on an earlier conceit that he would not attempt a reconstruction of Indo-European poetic pragmatics, Watkins conjectures that a ritual on a certain inscription involved an undescribed set of actions, which were also ritualized (Watkins 137). He then uses two different versions of the same ritual spell to demonstrate that the spells were meant to be dialogic, which - if liturgical - meant that it was also a performance. Resuming his comparativist role, Watkins then compares this dialogic performance with poems of similar character found in the rg veda.

Along with in-depth case studies like the one above in part II Watkins discusses more abstract theoretical figures of Indo-European poetics (especially in chapter I3 (Watkins I65ff.)) that can be reconstructed on the basis of evidence from the various descendant languages. These discussions are fundamental to the work that Watkins does in the latter half of the book, as they allow him to construct an abstract syntactic frame work into which he may insert lexemes of the proper syntactic category. 
Part III is an examination of and an argument for the antiquity of a strophic style in Indo-European (Watkins vii). I think that this section most importantly allows Watkins to demonstrate the theory put forth in the parts previous. Moreover, it allows him to concretely reconstruct an IndoEuropean poetic form in which the formula he reconstructs later may find context. For readers interested in Watkins' novel theories about the dragonslaying myth, this section may be referenced only when the rest of the text requires, and for those interested in the general theory of comparative Indo-European poetics, it may optionally be read to reinforce the previous material; however, it is a clear departure from parts I and II in that it presents the reader with poetics primarily in practice, as opposed to only mostly in theory.

The second half of the book, consisting of parts IV through VIII, is the result of Watkins' new research in the field: he builds up a theory about a dragon-slaying myth in the Indo-European poetic tradition, and more

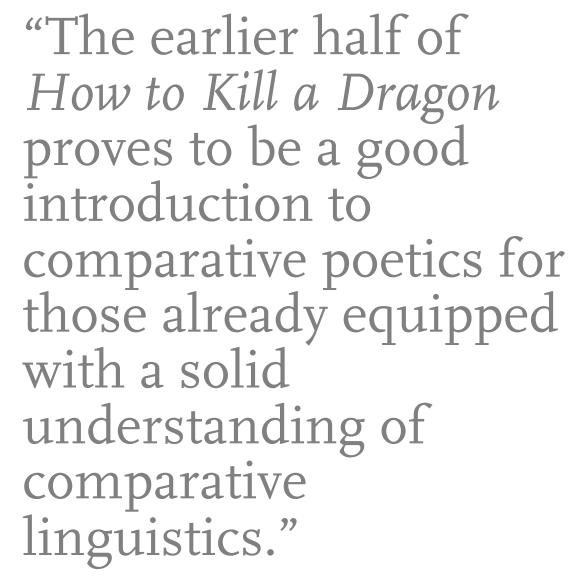
specifically the formula "HERO SLAY SERPENT". Watkins effectively works backwards to prove the reconstruction, assuming that the formula exists in some refined version of this "basic form", based on evidence from a small and homogenous corpus (Watkins 30I). He also prematurely dictates the parameters of the basic form, stating that the verb be some derivation of the Proto-Indo-European $\mathrm{g}^{\mathrm{w}} \mathrm{hen}$ and allowing for the variation that comes with optional phrases of instrumentality or accomplicity. Watkins follows this with a discussion of the various changes that occur in the different languages, proving the interrelatedness of the reflexes of the formula at the same time, spending the greatest portion of time on Indo-Iranian, Anatolian (represented solely by Hittite), and Greek. At no point, however, does Watkins expend any effort to demonstrate that the formula is in any way specific or unique to Indo-European, though he does concede that "it may be quasi-universal" (Watkins 297).

While Watkins makes a compelling argument, much of the effect comes from the size of the argument. The earlier half (parts I through III) of How to kill a dragon proves to be a good introduction to comparative poetics for those already equipped with a solid understanding of comparative linguistics; those with experience in the Classics will also find the material accessible, though perhaps not as much so as linguisticallytrained philologists. Additionally, the case studies in part II are quite modular, and with proper tuition may be studied more-or-less independently of one another. Finally, the extensive bibliography provided at the end of the book, along with a detailed index of passages cited, proves invaluable to the curious student.

The second half of the book (parts IV through VII), in which Watkins puts forth his own research, proves less rewarding and more 
frustrating for the reader. Often vague, even in the conclusion, one wonders what has actually been concluded. Further, Watkins does nothing to convince the reader of the "Indo-European-ness" of his chosen formula: the comparative approach is an implicit argument for a derivational, genetic explanation for the parallelisms that exist cross-linguistically, and nothing is proposed to explicitly discredit alternative explanations; however, that such alternatives are to be automatically judged inferior to geneticism may be a conceit of linguists engaging in comparative poetics. 